\title{
Partisipasi Masyarakat Lokal Dalam Pelestarian Istano Basa Pagaruyung Kabupaten Tanah Datar Sumatera Barat Sebagai Daya Tarik Wisata
}

Khalida Prima Zolaa,1 ,I Made Adikampanaa,2

1kprimazo@gmail.com, ${ }^{2}$ adikampana@unud.ac.id

a Program Studi S1 Destinasi Pariwisata, Fakultas Pariwisata,Universitas Udayana, Jl. Dr. R. Goris, Denpasar, Bali 80232 Indonesia

\section{Abstract}

The purpose of this study was to determine local community participation to preservation of Istano Basa Pagaruyung as tourism attraction. Data collection procedures using observation and interviews. Data were analyzed using qualitative descriptive technique. The results based on the description of local community participation in supporting the preservation of Istano Basa Pagaruyung, Tanah Datar regency, West Sumatera as tourist attraction. The types of local community participation to support preservation of Istano Basa Pagaruyung is participation in implementation and participation in taking of benefits. While on the type of participation in decision making and evaluation, the local community does not have an active role. Local communities participate as man power, treasure an skills. While there is no participation of idea or thought that have done by local resident around Istano Basa Pagaruyung tourist attraction.

Keywords: Participation, community, concervation

\section{PENDAHULUAN}

Adi (2007) mendefinisikan partisipasi masyarakat mrupakan peran serta masyarakat dalam proses pengindentifikasi potensi dan masalah yang ada di komunitas lokal, pemilihan dan pengambilan keputusan tentang alternatif penyelesaian masalah dan peran serta masyarakat lokal dalam proses evaluasi perubahan yang terjadi. Keikutsertaan masyarakat terhadap pelaksanaan dapat diukur secara nyata dalam kegiatan yang dilaksanakan, adalah bentuk kegiatan yang telah dilaksanakan dalam kegiatan fisik. Dengan begitu, ukurannya adalah bagaimana masyarakat berperan serta dalam hubungannya dengan kegiatan yang ada didaya tarik wisata. keikutsertaan tersebut berupa uang, material, dan juga tenaga.

Kabupaten Tanah Datar memiliki sumber daya budaya yang berwujud (bangunan, situs, ertefak) maupun yang tidak berwujud (kesenian, cerita rakyat dan adat istiadat). Salah satu peninggalan budaya di Tanah Datar adalah Istano Basa Pagaruyung. Untuk menjaga dan melestarikan Istano Basa Pagaruyung pemerintah sebagai pengelola membuat sebuah komunitas di masyarakat yaitu sebuah komunitas kesenian guna melestarikan budaya Minangkabau. Nilai penting dalam komunitas lokal adalah nilai sejarah, nilai keindahan, nilai budaya, nilai moral, nilai pendidikan dan nilai agama yang semua itu dapat dijadikan sebagai sebuah komunitas masyarakat lokal Minangkabau.
Istano Basa Pagaruyung adalah sebuah replika dari peninggalan kerajaan Minangkabau, yang dahulu sempat dibakar oleh Belanda. Bagunan ini dilengkapi dengan ukiran khas falsafah dan budaya Minangkabau. Istano Basa Pagaruyung selain dijadikan daya tarik wisata, merupakan sebuah pusat pengembangan, pelestarian adat budaya Minangkabau dan menjadi sebuah museum adat. Istano Basa Pagaruyung merupakan sebuah representasi dari budaya Minangkabau yang sudah menjadi icon wisata Minangkabau. (Dinas BUDPARPORA)

Masyarakat berperan penting dalam menunjang pembangunan pariwisata. Pelestarian Istano Basa Pagaruyung memerlukan partisipasi masyarakat lokal melalui perencanaan atau program-program yang mampu memadukan antara kepentingan pelestarian (conservation) dan pembangunan pariwisata (tourism development). Atas dasar pemikiran diatas maka penelitiaan ini berfokus kepada Partisipasi Masyarakat Lokal dalam Mendukung Pelestarian di Istano Basa Pagaruyung Kabupaten Tanah Datar, Sumatera Barat.

\section{TINJAUAN PUSTAKA}

\section{1 Pariwisata Budaya}

Sillberbeg (1995) dalam Damanik (2013) mengartikan pariwisata budaya adalah kunjungan wisatawan dari luar destinasi yang didorong oleh ktertarikan pada peninggalan sejarah, kesenian, ilmu pengetahuan, dan gaya hidup yang dipunyai oleh masyarakat sekitar. 
Kristiningrum (2014) berpendapat bahwa pariwisata budaya adalah wisata yang terdapat nilai budaya tentang adat istiadat, keagamaan dan warisan kebudayaan.

Pariwisata budaya berhubungan dengan daya tarik wisata budaya. Penjelasam Remcana Induk Pembangunan Kepariwisataan Nasional (RIPPARNAS) pasal 15 ayat (1) huruf b mendefinisikan daya tarik wisata budaya adalah daya tarik berupa olah cipta, rasa, dan karsa manusia sebagai makhluk budaya.

\section{2 Pelestarian}

Pelestarian menurut Alwasih (2006) merupakan upaya yang berdasar akan faktor yang mendukung hal yang dilestarikan. Proses pelestarian tentang strategi yang didasari pada kebutuhan.

Menurut Alwasih ada tiga langkah mengenai revitalisasi budaya, adalah:

1. Pemahaman

2. Perencanaan

3. Pembangkitan kreatifitas terhadap kebudayaan

Segala hal dilakukan oleh pihak pengelola dan masyarakat lokal untuk menjaga peninggalan dan budaya yang ada di Istano Basa Pagaruyung, seperti barang-barang bersejarah, kebersihan di sekitar area Istano Basa Pagaruyung, serta menjaga keunikan yang ada di daya Tarik wisata Istano Basa Pagaruyung.

\section{3 Partisipasi Masyarakat}

Rahardjo (1996) dalam Mardijino (2008) berpendapat bahwa pertisipasi dapat merupakan keikutsertaan masyarakat untuk sebuah kegiatan. Partisipasi msyarakat dalam program pembangunan, pengelolaan dan pelestarian.

Partisipasi merupakan sebuah dukungan masyarakat atau telah ditentukan oleh perencana sebagai suatu kesediaan agar membantu keberhasilan sebuah kegiatan sesuai dengan kemampuan masyarakat untuk berbagai kegiatan yang mensejahterakan kehidupan masyarakat lokal.

\subsection{Jenis dan Bentuk Partisipasi}

Cohen dan Uphoff (1977) dalam Dwiningrum (2011) menyebutkan jenis partisipasi yaitu:
1. Partisipasi dalam pengambilan keputusan adalah penentuan tentang ide atau gagasan yang melibatkan kepentingan bersama. Hal yang merupakan partisipasi masyarakat dalam pengambilan keputusan adalah diskusi, kehadiran masyarakat dalam suatu kegiatan, serta memberikan ide dan gagasan terhadap suatu kegiatan yang dilaksanakan.

2. Partisipasi msyarakat dalam pelaksanaan adalah keikutsertaan pemerintah, masyarakat serta pelaku yang terlibat dalam suatu kegitan, sebagai sumber pembangunan. Keikutsertaan masyarakat dalam pelaksanaan suatu kegiatan adalah sebuah kunci kesuksesan suatu kegiatan yang dilaksanakan.

3. Partisipasi masyarakat dalam pengambilan manfaat adalah berhubungan dengan kualitas dan kuantitas pelaksaan suatu kegiatan.

4. Partisipasi masyarakat dalam evaluasi berhubungan dengan segala kegiatan. Tujuan dari keikutsertaan masyarakat lokal dalam penilaian suatu kegiatan adalah telah terlaksananya suatu kegiatan yang telah direncanakan secara menyeluruh.

Iskandar (1994) dalam Huraerah (2004) memperinci bentuk partisipasi yaitu:

a. Partisipasi masyarakat dalam bentuk buah pikiran adalah masyarakat memberikan sebuah ide, saran dan kritikan dalam sebuah kegiatan yang akan dilaksanakan.

b. Partisipasi masyarakat dalam bentuk tenaga adalah keikutsertaaan masyarakat dalam kegiatan dalam pembanguan, pengelolaan dan pelestasian secara suka rela.

c. Partisipasi masyarakat dalam bentuk harta benda adalah masyarakat memberikan materi berupa uang, barang, penyediaan sarana dan fasilitas untuk membantu kegiatan.

d. Partisipasi masyarakat dalam bentuk keterampilan adalah masyarakat lokal berperan serta untuk memantu kegiatan yang dilaksanakan dengan bantuan keahlian yang dimiliki. 


\section{METODE PENELITIAN}

Daya tarik wisata Istano Basa Pagaruyung terletak di Nagari atau Desa Pagaruyung Kecamatan Tanjung Emas. Jarak Istano Basa Pagaruyung dari Padang yang merupakan Ibukota Provinsi Sumatera Barat adalah sekitar $106 \mathrm{Km}$. Sedangkan jarak dari Batusangkar yang merupakan Ibukota Kabupaten adalah sekitar $5 \mathrm{Km}$. Penelitian ini menggunakan metode deskriptif kualitatif. Penelitian ini menggukan teknik observasi, wawancara mendalam dan studi kepustakaan. Sugiyono (2007).

Penelitian ini menggunakan teknik penentuan informan purvosive sampling. Sugiyono (2007) mendefinisikan menentukan informan. Pada penelitian ini ditentukan informan kuncinya yaitu pengelola daya tarik wisata Istano Basa Pagaruyung dan selanjutnya pengelola merekomendasikan masyarakat lokal yang ikut terlibat dalam partisipasi masyarakat lokal terhadap pelestarian daya Tarik wisata Istano Basa Pagaruyung

\section{HASIL DAN PEMBAHASAN}

\subsection{Gambaran Umum Istano Basa Pagaruyung}

Daya tari wisata Istano Basa Pagaruyung terletak di Kabupaten Tanah Datar, Sumatera Barat. Daya tarik wisata ini dapat di jangkay menggukan transportasi roda dua dan transportasi roda empat.

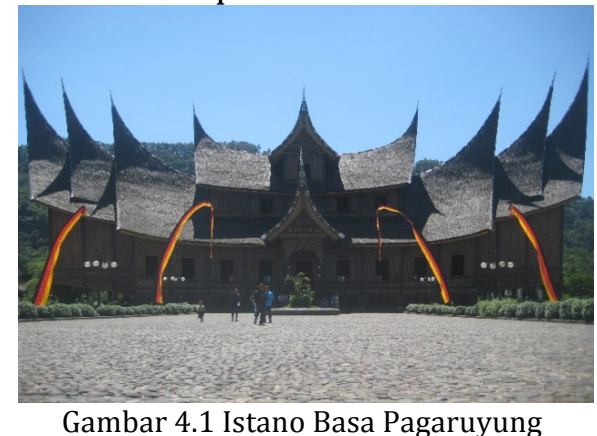

Istano Basa Pagaruyung, merupakan sebuah icon pariwisata di Sumatera Barat. Daya tarik wisata Istano Basa Pagaruyung yang sekarang merupakan sebuah tiruan dari bangunan Istano Basa Pagaruyung yang dibangun pada zaman kerajaan. Daya tarik wisata Istano Basa Pagaruyung 11 gonjong atau atap, 72 tonggak atau tiang, 3 lantai, surau atau mushola, tabuah, tempat penyimpanan padi atau yang disebut dengan rangkiang patah 9. Terdapat ukiran khas Minangkabau yang mempunyai arti tentang sejarah dan budaya Minangkabai. (Dinas BUDPARPORA Tanah Datar)

Istano Basa Pagaruyung adalah pusat budaya Minangkabau. Di dalam Istano Basa Pagaruyung terdapat berbagai benda kebudayaan yang berasal dari Sumatera Barat, serta berbagai informasi terkait daya tarik wisata Istano Basa Pagaruyung tersebut.

Pada panggung Istano Basa Pagaruyung ini terdapat area khusus penyewan pakaian adat Minangkabau serta hiasan kepala (suntiang) untuk wisatawan yang berkunjung ke daya tarik wisata Istano Basa Pagaruyung. Istano Basa Pagaruyung terdiri dari tiga lantai, pada lantai pertama terdapat pakaian adat dan benda-benda budaya Minangkabau. Sedangkan pada lantai dua pada dinding nya terdapat ukiran-ukiran khas Minangkabau pada dindingnya dan juga terdapat senjata peninggalan budaya Minangkabau. Pada lantai tiga hanya terdapat ruangan lepas.

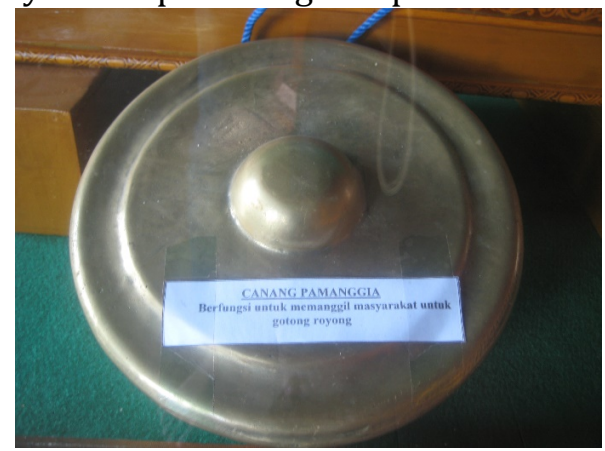

Gambar 4.2 Benda Kebudayaan Minangkabau (Canang Pamanggia)

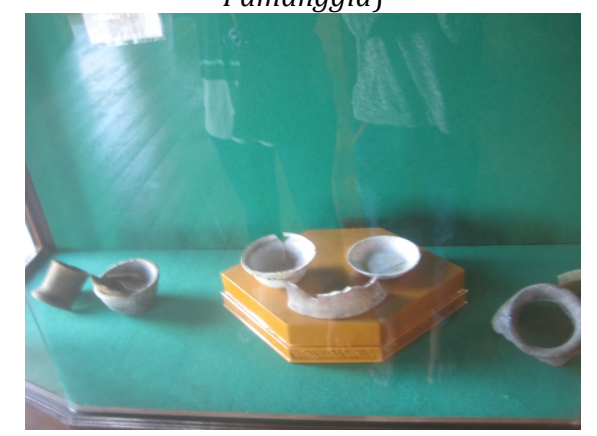

Gambar 4.3 Benda Kebudayaan Minangkabau 


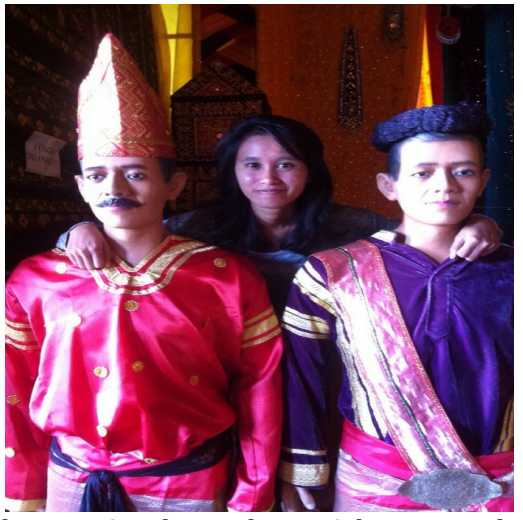

Gambar 4.4 Gambar Pakaian Adat Minangkabau

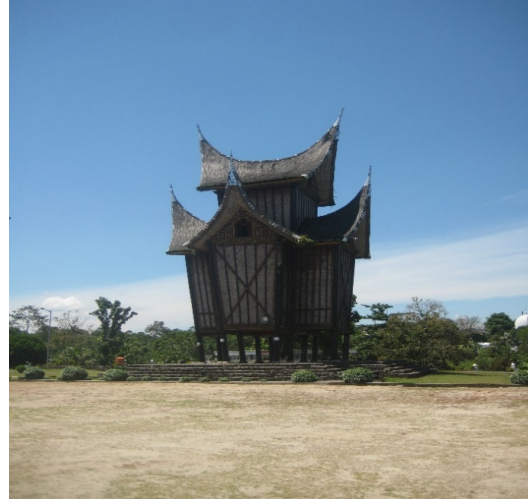

Gambar 4.5 Rangkiang Istano Basa Pagaruyung

Istano Basa Pagaruyung ini adalah icon pariwisata di Sumatera Barat. Sehingga tidak hanya wisatawan nusantara yang berkunjung ke daya tarik ini tetapi daya tarik Istano Basa Pagaruyung di kunjungi oleh wisatawan mancanegara seperti wisatawan dari Malaysia, Singapura, Brunei serta beberapa wisatawan dari Eropa.

\subsection{Partisipasi Masyarakat Lokal dalam Pelestarian Istano Basa Pagaruyung}

Kegiatan kepariwisataan akan berhasil jika didukung oleh masyarakat lokal dalam komunitas yang ada di masyarakat itu sendri. Dengan adanya keterlibatan atau partisipasi masyarakat dalam melaksanakan kegiatan kepariwisataan bisa berkembang dengan baik dan harmonis. Dalam penelitian ini partisipasi masyarakat lokal dalam mendukung pelestarian Istano Basa Pagaruyung tentulah memberikan kontribusi bagi Istano Basa Pagaruyung dan stakeholder yang terlibat langsung dalam kegiatan tersebut. Jenis dan bentuk partisipasi masyarakat lokal dalam mendukung pelestarian Istano Basa Pagaruyung yaitu:

\section{Jenis Partisipasi Masyarakat}

Dari berbagai program dalam pelestarian Istano Basa Pagaruyung yang sudah dilaksanakan, hal tersebut berhubungan dengan keikut sertaan komunitas lokal di daya tarik wisata Istano Basa Pagaruyung. Jenis keikutsertaan konumitas lokal yang ada di Istano Basa Pagaruyung menurut Cohen dan Uphoff (1977) dalam Dwiningrum (2011) adalah keikutsertaaan dalam pelaksanaan kegiatan pelestarian Istano Basa Pagaruyung dan partisipasi masyarakat dalam pengambilan manfaat, yang mana dalam pengambilan manfaat tidak terlepas dari hasil pelaksanaan kegiatan yang dicapai. Dalam hal ini, ketika masyarakat lokal secara langsung maupun tidak langsung ikut membantu dalam segala kegiatan di daya tarik wisata, berarti masyarakat akan mendapatkan manfaat baik itu manfaat yang berwujud atau tidak berwujud. Dalam hal ini masyarakat menggunakan keterampilan atau keahlian yang telah mereka miliki, dimana dari keterampilan tersebut masyarakat akan membantu apa yang dibutuhkan wisatawan, sehingga adanya interaksi antara wisatawan dengan masyarakat dan serta membantu dalam kegiatan pelestarian Istano Basa Pagaruyung sebagai daya tarik wisata. Manfaat yang diterima masyarakat lokal berupa hasil finansial yang bisa membantu kehidupan masyarakat lokal itu sendiri.

Sedangkan masyarakat lokal di Istano Basa Pagaruyung belum terlibat dalam partisipasi pengambilan keputusan, karena Pengelola Istano Basa Pagaruyung tidak melibatkan masyarakat lokal secara langsung dalam pengambilan keputusan yang terkait dengan pelaksanaan dan pelestarian Istano Basa Pagaruyung. Pengambilan keputusan dalam pelaksanaan dan pelestarian Istano Basa Pagaruyung hanya dilakukan oleh pengelola Istano Basa Pagaruyung, yaitu Dinas Pariwisata dan Olahraga Tanah Datar. Sehingga partisipasi masyarakat dalam pengambilan keputusan bisa dikatakan rendah atau tidak ada. Ketika berjalannya suatu evaluasi dalam kegiatan pelaksanaan dan pelestarian Istano Basa Pagaruyung sebagai daya tarik wisata, masyarakat tidak dilibatkan oleh pengelola Istano Basa Pagaruyung, sehingga masyarakat tidak mengetahui kekurangan yang harus diperbaiki untuk memajukan dan melestarikan 
Istano Basa Pagaruyung sebagai daya tarik wisata kedepannya.

Dari uraian diatas, jenis partisipasi masyarakat yang terdapat pada Istano Basa Pagaruyung adalah:

\section{Membentuk Komunitas Kesenian}

Partisipasi masyarakat lokal dalam pelestarian sudah melibatkan seluruh lapisan masyarakat sekitar desa di daya tarik wisata Istano Basa Pagaruyung dengan membentuk komunitas kesenian seperti randai, silek, dan tari daerah agar komunitas yang dibentuk bisa ikut berpartsisipasi dalam event yang akan diadakan oleh pengelola Istano Basa Pagaruyung, sehingga dengan demikian bisa mengenalkan budaya Minangkabau kepada wisatawan dan dengan hal tersebut masyarakat telah ikut berpartisipasi dalam melestarikan Istano Pagaruyung sebagai daya tarik wisata. Seperti yang dikatakan oleh salah satu masyarakat sekitar daya tarik wisata Istano Basa Pagaruyung.

"Dalam pelestarian Istano Basa Pagaruyung, masyarakat lokal hanya ikut dalam event yang akan diadakalan oleh pengelola, dengan cara masyarakat mempunyai komunitas kesenian dan tampil dalam event yang di adakan di Istano Basa Pagaruyung."

(Wawancara penulis, 6 Mei 2015)

2. Membuka Kios Makanan dan Minuman

Adanya kios pedagang makanan/minuman di sekitar Istano Basa Pagaruyung memberikan keuntungan tersendiri bagi masyarakat lokal sekitar. Sangat berpengaruh terhadap pendapatan dan perekonomian mereka, apalagi di dalam kawasan Istano Basa Pagaruyung wisatawan tidak boleh membawa makan dan minuman, sehingga wisatawan akan belanja setelah atau sebelum mengelilingi Istano Pagaruyung dan itu akan meningkatkan pendapatan masyarakat sekitar.

Penuturan seorang pedagang makanan yang ada di sekitar Istano Pagaruyung:

"Kami tidak boleh masuk dalam kawasan istano untuk berjualan. Tetapi walaupun demikian wisatawan pasti akan membeli makanan atau minuman yang kami jual di karenakan di kawasan istano tidak diperbolehkan untuk membawa minuman."

(Ratih, wawancara penulis 6 Mei 2015)

\section{Membuat Cinderamata}

Partisipasi masyarakat sekitar Istano Basa Pagaruyung adalah menjual hasil kerajinan khas Minangkabau yang dibuat oleh komunitas masyarakat sekitar, sehingga hasil dari kerajinan tersebut dijadikan cinderamata oleh wisatawan yang berkunjung ke Istano Basa Pagaruyung. Disamping itu, masyarakat lokal juga mengajarkan wisatawan cara membuat kerajinan khas Minangkabau yang hasilnya bisa dibawa oleh wisatawan sebagai cinderamata. Bukan hanya dalam bidang kesenian, tetapi dalam bidang kuliner masyarakat lokal juga menjual makanan khas Minangkabau sebagai cindera mata yang bisa di bawa oleh wisatawan. Komunitas Ibu PKK (Permberdayaan dan Kesejahteraan Keluarga) di sekitar Istano Basa Pagaruyung ini juga mengajarkan wisatawan cara membuat berbagai macam makan khas Minangkabau.

\section{Bentuk Partisipasi Masyarakat}

Bentuk partisipasi masyarakat menurut Iskandar (1994) dalam Huraerah (2004) adalah partisipasi dalam bentuk tenaga, harta benda dan keterampilan. Partisipasi buah pikiran adalah dimana masyarakat memberikan sebuah ide atau gagasan mengenai pengembangan, pelaksanaan dan pelestarian. Dalam hal ini, partisipasi masyarakat lokal dalam bentuk pikiran atau memberikan ide terkait pelestarian Istano Basa Pagaruyung sebagai daya tarik wisata belum dilakukan oleh masyarakat, dikarenakan masyarakat lokal tidak terlibat dalam pengelolaan Istano Basa Pagaruyung. Dilihat dari jenis partisipasi dalam pengambilan keputusan dan evaluasi, masyarakat tidak ikut berperan serta terkait dengan diskusi dan tanggapan terhadap kegiatan yang akan dilaksanakan.

Dari uraian diatas dapat dilihat bahwa bentuk partisipasi masyarakat lokal dalam pelestarian Istano Basa Pagararuyung adalah:

1. Menjaga Kebersihan Daya Tarik Wisata Istano Basa Pagaruyung

Kebersihan daya tarik wisata Istano Basa Pagaruyung bukan hanya menjadi tanggung jawab pengelola, namun partisipasi masyarakat sangat dibutuhkan agar kebersihan area sekitar Istano Basa Pagaruyung tetap terjaga. Untuk menjaga dan melestarikan Istano Basa Pagaruyung, pengelola dan masyarakat berkerja sama menetapkan dua kali seminggu 
mengadakan kerja bakti atau gotong royong untuk membersihkan area wisata, masyarakat melakukan perbaikan bagunan yang telah mengalami kerusakan dan masyarakat juga membangun taman yang luas di daya tarik wisata Istano Basa Pagaruyung.

\section{Promosi}

Dalam bentuk pelestarian Istano Basa Pagaruyung masyarakat lokal sering melakukan kegiatan mempromosikan Istano Basa Pagaruyung dengan melalui mulut ke mulut serta berbagai media sosial.

\section{Memberikan Sumbangan}

Masyarakat lokal menyumbangkan materi berupa uang, barang, penyediaan sarana dan fasilitas untuk kepentingan pelaksaan kegiatan kepariwisataan serta pelestarian Istano Basa Pagaruyung sebagai daya tarik wisata.. Masyarakat berpartisipasi berupa pemberian sumbangan uang untuk keperluan pembangunan di kawasan daya tarik wisata. Seperti penuturan pengelola Istano Basa Pagaruyung, yaitunya:

"Pada tahun 2007 Istano Basa Pagaruyung ini pernah mengalami kebakaran. Sebelum pemerintah memberikan bantuan kepada Istano Basa Pagaruyung, masyarakat sekitar turut memberikan sumbangan materi untuk pembangunan kembali bangunan Istano Basa Pagaruyung."

(Wawancara Penulis Mei 2016)

\section{Membentuk Berbagai Komunitas Desa}

Pengelola Istano Basa Pagaruyung bekerja sama dengan masyarakat lokal membuat komunitas desa guna mendukung pelestarian Istano Basa Pagaruyung. Pengelola dan masyarakat lokal mengadakan pelatihan untuk melestarikan kawasan wisata melalui kegiatan yang dilaksanakan dalam organiasi desa, seperti kegiatan dalam PKK (Permberdayaan dan Kesejahteraan Keluarga), ikatan pemuda pemudi desa dan komunitas kesenian yang ada di sekitar daya tarik wisata Istano Basa Pagaruyung.

\section{SIMPULAN DAN SARAN}

\subsection{Simpulan}

Berdasarkan penjabaran tentang partisipasi masyarakat lokal dalam pelestarian Istano Basa Pagaruyung, bahwa jenis partisipasi masyarakat lokal yang terdapat dalam pelestarian Istano Basa Pagaruyung adalah partisipasi masyarakat dalam jenis pelaksaan dan partisipasi masyarakat dalam jenis pengambilan manfaat. Sedangkan partisipasi masyarakat dalam jenis pengambilan keputusan dan jenis evaluasi, masyarakat tidak ikut berperan aktif. Sehingga membuat rendahnya partisipasi masyarakat lokal dalam pelestarian Istano Basa Pagaruyung. Pada bentuk partisipasi, masyarakat lokal berperan serta pada bentuk tenaga, partisipasi dalam bentuk harta benda, dan dalam bentuk keterampilan. Sedangkan tidak ada partisipasi buah pikiran yang telah dilakukan oleh masyarakat sekitar daya tarik wisata Istano Basa Pagaruyung.

\subsection{Saran}

Berdasarkan kesimpulan, dapat diberikan beberapa saran, sebagai berikut:

a) Pihak pengelola hendaknya melibatkan masyarakat dalam mengevaluasi kegiatan yang telah dilakukan, agar masyarakat bisa memberikan ide atau gagasanya mengenai pelestarian Istano Basa Pagaruyung.

b) Pemerintah hendaknya memberikan edukasi kepada masyarakat lokal tentang pentinya pelestarian Istano Basa Pagaruyung agar masyarakat bisa menjaga dan melestarikan budaya Minangkabau.

c) Masyarakat hendaknya menyadari betapa pentingnya pelestarian budaya, sehingga masyarakat harus berpartisipasi lagi dengan jenis partisipasi dalam pengevaluasian dan bentuk partisipasi dalam buah pikiran, agar dapat mengetahui kekurangan serta bisa memberikan ide atau gagasan agar Istano BasaPagaruyung bisa lebih baik.

d) Agar peninggalan budaya yang ada di Istano Basa Pagaruyung tidak punah, hendaknya para stakeholder dapat menjaga dan melestarikan serta memberikan interprestasi baru terhadap peninggalan kebudayaan, sehingga kelestarian dan pengembangan peninggalan kebudayaan dapat terjadi.

Daftar Pustaka:

Adi, Isbandi Rukminto. 2007. Perencanaan Partisipatoris Berbasis Asset Komunitas: Dari Pemikiran Menuju Penerapan. Depok: FISIP UI Press.

Alwasih, A. Chaedar. 2006. Pokoknya Sunda: Interprestasi Untuk Aksi. Bandung: Kiblat 
Vol. 6 No 1, 2018

Damanik., Phil Janiaton. 2013. Pariwisata Indonesia: Antara Peluang dan Tantangan. Yogyakarta: Pustaka Pelajar

Dinas BUDPARPORA Tanah Datar, 2014, Perkembangan Dan Pesona Wisata Kabupaten Tanah Datar Prov Sumatera Barat.

Dwiningrum, Siti Irene Astuti. 2011. Desentralisasi dan Partisipasi Masyarakat dalam Pendidikan. Yogyakarta: Pustaka Pelajar

Huraerah, Abu. 2008. Pengorganisasian \& Pengembangan Masyarakat : Model \& Srategi Pembangunan Berbasis Kerakyatan. Bandung: Humaniora.

Mardijono. 2008. Persepsi dan Partisipasi Nelayan terhadap Pengelolaan Kawasan Konservasi Laut Kota Batam. Semarang. Universitas Diponegoro.

Sugiyono. 2007. Metode Penelitian Kuantitatif Kualitatif dan R\&D. Bandung: Alfabeta. 